\title{
PROJETO DE EXTENSÃO: ALFABETIZAÇÃO DE CRIANÇAS POR MEIO DE SOFTWARE DE APRENDIZAGEM
}

Originais recebidos em: 26/02/2010

Aceito para publicação em: 15/07/2011

\section{Karina Matheus dos Santos \\ Universidade Federal de Santa Catarina karinalmofadinhas@hotmail.com}

\author{
Monique Stahnke \\ Universidade Federal de Santa Catarina \\ monique stahnke@hotmail.com
}

\section{Resumo}

$\mathrm{O}$ mundo digital desperta o interesse e a curiosidade dos alunos de diversas maneiras, abrindo possibilidades de ensino e aprendizagem. O software Mestre ${ }^{\circledR}$ (GOYOS; ALMEIDA, 1994) é uma ferramenta que busca as possibilidades do mundo digital, facilitando a aprendizagem sem erros. Com isso, iniciou-se o projeto Alfabetização de crianças por meio de softwares de aprendizagem no Colégio de Aplicação da UFSC, que objetivou propiciar inclusão digital e sugerir o uso de ferramentas digitais no repertório do professor. $\mathrm{O}$ projeto realizado na forma de acompanhamento e planejamento das aulas com uso do Mestre ${ }^{\circledR}$ por duas monitoras, durante seis meses. As participantes eram cinco alunas de uma turma do $1^{\circ}$ ano do ensino fundamental com idades entre 6 e 7 nos. Indicadas pela professora por achar que se beneficiariam com o projeto por apresentarem dificuldades maiores em relação à alfabetização ou outros tipos de dificuldade. Uma das alunas apresenta deficiência auditiva e usa implante coclear. Foram aplicados exercícios com uso do software Mestre ${ }^{\circledR}$ a partir do princípio de pareamento de estímulos. Observou-se que todas as alunas aumentaram a autonomia para responder às atividades e tarefas escolares ao longo do programa e ficaram mais confiantes para respondê-las da melhor forma que pudessem, permitindo às monitoras a formulação de diagnóstico e prognóstico a partir das hipóteses de escrita percebidas e o planejamento de um programa de aulas a partir das hipóteses de escrita de cada uma. Obtiveram-se conhecimentos em torno do que um software educacional pode e precisa para melhorar como ferramenta de ensino, evidenciando as vantagens da aprendizagem sem erros num programa de ensino que contemple a singularidade e respeite o ritmo dos alunos.

Palavras-chaves: Software de aprendizagem. Ensino-aprendizagem. Hipóteses de Escrita. Aprendizagem sem erros.

\begin{abstract}
The digital world awakens the interest and curiosity in students in several ways, opening possibilities in teaching and learning. The software Mestre ${ }^{\circledR}$ (GOYOS; ALMEIDA, 1994) is a tool that searches possibilities of the digital world, making easier to learn without mistaking. With this, the Children Literacy Through Learning Sotfwares project took effective place in UFSC's Colégio de Aplicação school, with the objectives of teaching in literacy, propiciating digital inclusion and suggest the use of digital tools in the teacher's repertoire. The project was done in the form of assistance and planning the classes with the use of Mestre ${ }^{\circledR}$ by two monitors, during six months. The participants were five female students from one class of the first year of the fundamental teaching level with ages ranging from 6 to 7 years old. They were indicated by their teacher who thought they would benefit from the project for presenting greater difficulties related to literacy or other kinds of difficulties - one of them had impaired hearing and wore a cochlear implant. Exercises were applied with the use of Mestre ${ }^{\circledR}$ from the stimuli pairing principle. It was observed that all students increased autonomy to answer the activities and school assignments throughout the program and became more self-confident to answer them the best way they could, allowing the monitors to conceive diagnosis and prognosis from the writing hypothesis perceived by them, planning a class program from each one of the students' Writing Hypothesis. It was obtained knowledges respecting what an educationl software may and needs to improve as a teaching tool, pointing the advantages of the learning without mistaking in a teaching program that contemplates singularity and respect for the each student's timing in learning.
\end{abstract}

Keywords: Learning software. Teaching and learning. Writing Hypothesis. Leanirg without mistaking. 


\section{INTRODUÇÃO}

O projeto de extensão "Alfabetização de Crianças por Meio de Softwares de Aprendizagem" iniciou-se do interesse por educação e pelas possibilidades que softwares educacionais apresentam. No ano de 2008, o software Mestre ${ }^{\circledR}$ (GOYOS; ALMEIDA, 1994) foi apresentado às extensionistas pelo Dr. José Gonçalves Medeiros, professor do Departamento de Psicologia da UFSC com projetos desde 2001 com o software. O programa despertou interesse por suas diversas possibilidades enquanto ferramenta educativa. Em 2009 iniciou-se o projeto de extensão supracitado com o objetivo de oferecer o serviço de ensinoaprendizagem através do software Mestre ${ }^{\circledR}$.

Uma atividade de extensão visa oferecer um serviço da universidade para a comunidade universitária e em volta dela. Percebeu-se que o projeto concebido seria muito proveitoso para os alunos mais jovens em sua alfabetização. Os objetivos iniciais eram promover a aprendizagem através de jogos eletrônicos, incluir os participantes digitalmente e sugerir ao repertório de ferramentas do professor alternativas ao modelo usual de aulas.

O projeto desenvolveu-se no Colégio de Aplicação da UFSC, com cinco crianças do Ciclo 1 (primeiro ano do ensino fundamental de nove anos). Elas nos foram indicadas pela professora como atrasadas em relação a sua turma quanto à alfabetização.

O software Mestre ${ }^{\circledR}$ é um programa de computador baseado no pareamento de estímulo e aprendizagem sem erros. Seu uso permite ensinar novos comportamentos ao repertório do aluno. Isso ocorre quando o professor ensina seu aluno um novo comportamento, a ler a letra "a", por exemplo, e este pode apresentar o comportamento: ler a nova letra sozinho (KUBO; BOTOMÉ, 2001).

A aprendizagem sem erros é uma maneira de planejar e proceder um programa de ensino de forma que os passos sejam tão pequenos que diminuem ou eliminam as possibilidades de erros. $\mathrm{O}$ aluno é reforçado a cada resposta dada, assim, fica sabendo como está se saindo e pode pensar imediatamente sobre seu erro, caso este ocorra (SIDMAN, 1985).

No software Mestre ${ }^{\circledR}$ são apresentadas perguntas curtas com múltiplas escolhas de respostas (com até três opções), facilitando a programação via aprendizagem sem erros. Várias pesquisas corroboram o aumento e refinamento do repertório desenvolvido ao utilizar o software Mestre ${ }^{\circledR}$ para aprender a ler, superando histórias de fracasso escolar (MEDEIROS et al.; 2004). 
O pareamento de estímulos ocorre quando um estímulo-modelo é pareado com um estímulo-escolha, e se essa relação é almejada, ela deve ser reforçada (ROSSIT, 2003). Dentro do software Mestre ${ }^{\circledR}$, o estímulo-modelo será uma figura, som, ou palavra; e o estímuloescolha poderá apresentar-se em forma de figura, palavra ou letras. Por exemplo: quando a atividade tem o estímulo-modelo som "bola", o usuário clica na tela. Nesse momento, aparecem estímulos-escolhas em forma de palavras; um deles será a palavra bola.

Ao iniciar um novo bloco de atividades dentro do programa, pareia-se um estímulomodelo conhecido, com um único estímulo-escolha desconhecido. Reforçando esta relação positivamente, propicia-se ao indivíduo a formação de um conceito. Essa forma diminui a possibilidade de ocorrência de erros e as chances de ocorrer evasão do processo de ensinoaprendizagem (ROSSIT, 2003).

Depois, repetindo o mesmo estímulo-modelo, incluímos mais estímulos-escolhas que não são almejados para pareamento com o estímulo-modelo. Em uma situação ideal, o sujeito já discrimina o estímulo-escolha correto quando apresentado novos estímulos, pois a relação foi estabelecida anteriormente (ROSSIT, 2003). Em cada aula do Mestre ${ }^{\circledR}$, propõe-se o estabelecimento de três signos a se formarem pelas relações de pareamento e reforço.

O paramento de estímulos permite que algumas relações de ensino sejam aprendidas mesmo que não sejam diretamente ensinadas. Assim, se uma aula é programada para ensinar a relação entre o som "bola" e a palavra escrita "bola" (A-B) e entre a palavra escrita "bola" e as letras que formam a palavra "bola" (B-C), a relação entre o som e as letras que formam a palavra bola (A-C) pode ser estabelecida pelo aluno (ROSSIT, 2003). Esses são os princípios da simetria e da transitividade, que baseiam as atividades nomeadas de "Equivalência". Estas visam testar a capacidade de nossos alunos de perceber essas relações.

Reforço positivo e punição são termos cunhados e usados pela escola psicológica behaviorista, e os estudos destes estímulos foram usados ao longo da história como formas de melhorar a aprendizagem de um novo comportamento. Quando o comportamento almejado é apresentado pelo sujeito, deve-se apresentar um estímulo que aumente a probabilidade de uma nova ocorrência dele; este estímulo é um reforço. O reforço positivo ocorre quando algo é ganho pelo sujeito, como um elogio ou o vídeo apresentado pelo Mestre ${ }^{\circledR}$ comunicando o acerto. $\mathrm{O}$ efeito reforçador de um estímulo é uma relação que não é dada a priori, ou seja, se constrói na relação do sujeito com o mundo. A punição visa diminuir um comportamento inadequado. A punição positiva acrescenta algo após o comportamento, como o vídeo do Mestre ${ }^{\circledR}$ que indica o erro da criança ou um pedido de silêncio da professora 
(CANABARRA, 2006).

O trabalho desenvolvido procurou se adequar ao processo singular de aprendizagem de cada um dos participantes. Para tanto, trabalhou-se a partir das Hipóteses de Escritas de cada participante para montar as aulas dentro do software Mestre ${ }^{\circledR}$. As Hipóteses de Escrita são criadas pelas crianças durante seu aprendizado, baseando-se em suas próprias observações e associações, para deduzirem a escrita de palavras que ainda não dominam (SOUZA, 2007).

Ferreiro e Teberosky (APUD GINDRI; KESKE-SOARES; MOTA, 2007) destacam as quatro Hipóteses de Escritas mais comuns: pré-silábica (o sistema escrito não tem relação com o falado, uma unidade gráfica corresponde a um significado), silábica (o sistema escrito ganha significado pelas sílabas, uma letra corresponde a um som da fala e representa toda a unidade silábica), silábico-alfabético (período no qual a escrita é regida por sílabas e fonemas, oscilando entre eles), e alfabético (apreensão da linguagem formal).

\section{MATERIAIS E MÉTODOS}

Participaram do projeto cinco alunas, todas do Ciclo 1 (primeiro ano do ensino fundamental que dura nove anos), e da mesma turma. Elas tinham entre 6 e 7 anos. Foram indicadas pela professora por estarem atrasadas em relação a sua turma quanto à alfabetização. A aluna $\mathrm{C}$ é deficiente auditiva e possui o implante coclear; foi indicada ao projeto para trabalhar sua oralidade. Apenas a aluna "E" já havia tido contato com o software Mestre ${ }^{\circledR}$ através de uma pesquisa acadêmica.

O projeto ocorreu em uma sala de informática do colégio: "Labrinq, um novo caminho para aprender a ler e escrever". A sala possui dez computadores, dos quais nove estavam em funcionamento. Havia também oito mesas e cadeiras comuns de salas de aula infantis, dois ares-condicionados e materiais diversos para alfabetização, como brinquedos que tratam deste tema e material de leitura infantil. Esse espaço é para o desenvolvimento de projetos de alfabetização.

Utilizaram-se apenas dois computadores por vez: um deles com fones de ouvido para não ocorrer interferência de sons. Havia apenas duas monitoras disponíveis, e foram aplicadas as atividades em duas alunas por vez, na sala, cada uma em seu computador, acompanhada por uma monitora. Algumas vezes foram usados três computadores para da assistência a três alunas simultaneamente, para privelegiar o atendimento a todas as participantes do projeto no curto tempo disponível - o horário cedido era destinado originalmente às atividades de 
brinquedoteca das alunas, que durava em torno de duas horas.

O software Mestre ${ }^{\circledR}$ foi a principal ferramenta do projeto. Desenvolvido no Laboratório de Aprendizagem Humana, Multimídia Interativa e Ensino Informatizado (LAHMIEI) da UFSCar, ganhou o I Concurso Nacional de Desenvolvedores de Software para Macintosh. Cópias do software são disponibilizadas pelos desenvolvedores através do site do laboratório.

O programa é utilizado para trabalhar e propiciar o processo de "ensinar e aprender", no qual, se tudo ocorrer adequadamente, o professor ensina um comportamento novo ao repertório do aluno, e este estará apto para apresentá-lo sempre que preciso. Ele tem por base os princípios de aprendizagem sem erros e pareamento de estímulos.

O programa possui um menu, ou tela de abertura, simples, com poucas opções de trabalho representados por desenhos ilustrativos que permitem ao usuário acessar as aulas ou editá-las. Os sujeitos do projeto tinham acesso apenas às telas de executar as atividades. Essa tela de atividades tem o fundo azul, o qual é divido em duas partes por uma linha vermelha. A parte superior da tela é onde o estímulo-modelo aparece. Quando o sujeito clica com o mouse em cima dele, surgem o(s) estímulo(s)-escolha(s); o sujeito, então, opta por um dos estímulosescolhas e segue um vídeo que indica o acerto ou erro da atividade (o vídeo é opcional; a escolha é programada antes de a atividade iniciar). Este programa aparentemente simples pode estabelecer relações de diversos tipos.

A cópia do software utilizada no projeto foi cedida pelo Professor Dr. Medeiros, assim como as atividades programas dentro do Mestre ${ }^{\circledR}$ (algumas aulas foram alteradas ao longo do projeto conforme as Hipóteses de Escrita das alunas). O programa possui 24 aulas organizadas em três blocos. Cada bloco tem uma parte de "ensino" e outra de "testes" - a Equivalência. Todo o programa de aulas foi concebido partindo dos princípios de pareamento de estímulos e aprendizagem sem erros.

As aulas de "ensino" têm suas atividades divididas em testes pré-ensino, testes pósensino (atividades dentro do programa sem o vídeo-reforço) e ensino de novas palavras, cujo conteúdo abrange substantivos concretos, números e cores (em atividades reforçadas). O teste pré-ensino verifica a aprendizagem anterior à aula, se o aluno já aprendeu os conceitos a que se intencionava trabalhar. Já o teste pós-ensino verifica o que o aluno aprendeu após a aula. Ambas são idênticas em conteúdo.

As aulas de Equivalência consistem em duas atividades: a primeira com reforço, bem curta, que se resume em lembrar as relações estabelecidas, preparando o aluno para a 
atividade seguinte. A segunda atividade, que é sem reforço, trabalha relações não ensinadas diretamente pelas aulas anteriores. Assim, podemos observar a ocorrência dos princípios de simetria e transitividade em cada bloco de aulas de cada aluna.

Nesta mesma parte do bloco de aulas de Equivalência, há uma última atividade especial chamada "Agrupamento", na qual, além dos princípios de simetria e transitividade, é verificado e pedido para que se leia palavras, cores e números juntos e se agrupem os conceitos aprendidos nas aulas sobre números, cores e substantivos; por exemplo, é pedido que o aluno leia: "dois magos roxos".

Foram aplicadas duas aulas do programa por dia a cada participante. O projeto funcionou por seis meses e era aplicado durante o horário da Brinquedoteca; contava com duas horas de duração, sendo utilizada meia hora para cada participante.

\section{RESULTADOS E ANÁLISE}

A seguir, serão apresentados resultados, descrição e análise do processo de ensino e aprendizagem de cada participante ao longo do projeto. Ao fim apresentam-se os resultados do software, quando aplicado de forma integrada, ultrapassando as formalidades limítrofes do objetivo único de alfabetização.

\subsection{Participantes}

A professora indicou primeiro "A", como sua aluna que apresentava mais dificuldade em sala de aula e parecia estar muito atrasada em relação à sua turma. Disse que "A" não respondia às atividades, requisitava acompanhamento constante e parecia não lembrar o que era passado em sala de aula.

Durante as atividades com o Mestre ${ }^{\circledR}$, a aluna "A" demonstrou grande capacidade ao responder a parte da aula que corresponde ao ensino (que apresenta os vídeos de reforço). Entende-se que "A" conseguia responder às atividades em que obtinha feedback imediato de acerto ou erro. Entretanto, seu desempenho caía na atividade pós-ensino, provavelmente por não ser programada com reforço.

No início, "A" procurava atenção das monitoras com comportamentos de conquista por graças (como sorrisos e brincadeirinhas), ao longo das várias atividades do programa, tal qual em sala de aula. Ao passo que as monitoras notaram as estratégias da participante - o que a motivava a fazer e a não fazer na sala de aula e no ambiente do programa - instaurou-se 
uma política de resistência a responder positivamente aos seus comportamentos de conquista por graça e, ao invés disso, responder positivamente a demonstrações de autonomia em qualquer interação que pudessem estabelecer.

Uma situação ilustrativa é quando "A" contava uma história ou um caso aparte dos assuntos de alfabetização e escola. Nisso, interrompia-se seu discurso e comentava-se que ela não estava concentrada em sua atividade. Enquanto o programa a reforçava nas atividades de ensino, apontava-se a ela o valor de seu acerto frente a sua dificuldade inicial de se concentrar.

Com o tempo, ela passou a ser mais autônoma, dependendo muito mais do reforço do programa para lhe dizer se está certa, do que o das monitoras. O comportamento de conquista por graça diminuiu drasticamente, ocorrendo apenas quando o programa não apresenta reforço. Não se supõe que o comportamento de realizar a atividade com o objetivo natural de acertar tenha sido devidamente incorporado em seu repertório. Ela continuou a depender da ajuda e do reforço da professora ou da estagiária durante as atividades em sala de aula, constantemente demonstrando não desejar dar a resposta certa, mas sim manter a atenção de quem the ajuda. Contudo, a professora nos informou que "A" deu um salto em autonomia na sala de aula depois do seu ingresso no projeto, procurando responder a atividade sozinha antes de solicitar ajuda (um comportamento não demonstrado anteriormente).

Avalia-se nesse caso que o Mestre ${ }^{\circledR}$ ajuda a aluna a ser cada vez mais propícia a se sentir reforçada pelo acerto e não pela atenção que recebe, o que tem se refletido em sala de aula. Entretanto, o ambiente que o programa proporciona é amplamente reforçador (a cada pequeno passo durante o ensino ela recebe o feedback) ao passo que, na sala de aula, o resultado ocorre em menor intensidade. Assim, "A" volta ao comportamento de pedir atenção mesmo que não seja acertando. Para ela seria necessário mais tempo no projeto para que sua autonomia diante do acerto ou erro fosse assegurada.

Uma questão que fica é a avaliação do desempenho da participante "A", que, ao ser reforçada pelo programa, mostra verdadeira capacidade e não demonstra o mesmo desempenho nas atividades sem reforço. $\mathrm{O}$ resultado de suas atividades reforçadas ficam por volta de $90 \%$ de acerto, enquanto apresenta apenas metade de acertos nos exercícios sem reforço. Suas relações formadas por transitividade e simetria só estão garantidas na presença do reforço, acertando $100 \%$ das atividades de equivalência de palavras e números e $83 \%$ de cores. Suas relações de alfabetização foram desenvolvidas; a aluna consegue identificar o significado da palavra escrita e escrevê-la corretamente sem auxílio, mas o nível só poderá ser 
constatado numa situação em que a participante "A" considerar ler mais estimulante e prazeroso do que receber atenção de suas educadoras.

A segunda menina a ser indicada foi "B". Ela veio ao projeto para "reforçar sua alfabetização", visto que seu desempenho em sala de aula era menor do que de seus colegas. Seu caso era semelhante ao da aluna "A": "B" também requisitava atenção, tinha comportamentos de conquista por graça, mas seu desempenho em sala de aula era melhor que o de sua amiga "A".

Seu desempenho geral no Mestre ${ }^{\circledR}$ era menor que o de sua amiga de caso semelhante. Em seus comportamentos de conquista por graça, ela persistia muito mais para obter resposta positiva de suas educadoras. Entretanto, esse comportamento não parecia ser tão forte em sala de aula, visto que a professora e a estagiária queixavam-se muito mais da solicitação de atenção de "A". De acordo com a professora, "B" respondia às atividades em sala de aula quando não conseguia atenção (diferente de "A").

Durante as atividades, "B" fazia algumas exigências para continuá-las, as quais, ao não ser atendidas devido a impossibilidades concretas, insistia em reivindicá-las através de demonstração de sofrimento e frustração em torno do seu pedido ignorado. Essa relação prejudicou o processo de aprendizagem, de forma muito mais significativa do que em sala de aula, onde era atendida, pois assim as educadoras eram menos incomodadas por ela. "B" deixou de fazer várias atividades, procrastinava e muitas vezes teve um desempenho ruim, mesmo em atividades que já havia respondido certo.

Seu desempenho geral no Mestre ${ }^{\circledR}$, apesar disso, foi bom e equilibrado ao longo do processo. Seu descaso com as atividades de teste pré-ensino e teste pós-ensino foi evidente, porém, diminuído em relação à participante "A": seus resultados em pós-ensino muitas vezes eram bons (acima de 70\%), o que demonstrava certa animação em continuar a atividade que vinha acertando. Apesar do equilíbrio no desempenho, no comportamento não se pode dizer o mesmo, como ao fazer exigências de forma a se achar em situação de privilégios sobre suas colegas ou de perturbar as atividades de sua colega com barulhos e manhas persistentes.

$\mathrm{O}$ esforço das monitoras em resistir o comportamento dela de conquista por graça contribuiu para o seu desempenho, demonstrado em seus resultados cada vez melhores. Assim como para "A", o principal benefício foi a autonomia desenvolvida (ainda que "B" não tenha se demonstrado tão autônoma quanto "A" ao final do projeto). Para "B" o programa auxiliou muito em seu desempenho na alfabetização e contribuiu com a construção de uma relação estimulante de ensino-aprendizagem. 
A terceira aluna que foi encaminhada não possuía nenhuma dificuldade de aprendizagem ou atraso em relação à sua turma. Aqui codificada por "C", é deficiente auditiva e utiliza implante coclear, portanto, não identificava sons com facilidade. A professora a encaminhou para o projeto por considerar o programa Mestre ${ }^{\circledR}$ uma boa ferramenta para ajudá-la a melhorar a habilidade de identificar sons da fala.

"C" não apresentou dificuldades em identificar e escrever as palavras, apenas precisou de ajuda para identificar os sons e ruídos da fala (consoantes). A ajuda em sala de aula e durante o projeto foram diferentes: em sala de aula, a professora e "C" tinham alguns códigos para as consoantes mais difíceis, que ajudavam " $\mathrm{C}$ " a pronunciar corretamente, ao passo que, em nosso projeto, desconhecíamos esse código. Usava-se LIBRAS e, na maioria das vezes, usava-se também uma pronúncia cuidadosa. Como recurso adicional, "C" podia sentir a vibração no pescoço da monitora para imitar a consoante.

No final do trabalho, a aluna conseguia identificar a maioria das palavras sem precisar recorrer às monitoras, conseguindo replicar os sons ouvindo-os direto do programa, tornando-se mais autônoma. Precisava de monitoria apenas para as palavras de som muito similar, como "bolo" e "bobo".

"D" nos foi encaminhada depois de "A", "B" e "C". A demanda apresentada era de que "D" estava um pouco atrasada, mas não tanto quanto "A" ou "B". A professora estava em dúvida sobre mantê-la ou não no projeto, por isso ela foi encaminhada posteriormente em relação às participantes iniciais. " $D$ " demonstrou expectativa de que a atividade fosse fácil e divertida, mas seu resultado foi insatisfatório no primeiro dia. Ela demonstrou frustração durante todo o ensino e não quis fazer a atividade seguinte.

Percebeu-se que "D" estava com mais dificuldade para resolver as atividades do Mestre ${ }^{\circledR}$ que as outras meninas. Verificou-se de início que " $D$ " identificava vogais corretamente (como demonstrou nas poucas vezes em que escreveu algumas palavras), entretanto, a princípio não utilizava nem desta hipótese de escrita, sendo exaustivo motivá-la a exibir qualquer resposta ao programa - certa ou errada.

A maioria de suas respostas, em boa parte do programa de aulas, eram tentativas aparentemente aleatórias exibidas com certo descaso percebido pelas monitoras (com consoantes ou vogais não presentes nas palavras). Ela também generalizava estímulos anteriormente pareados com um modelo, cometendo erros repetitivos (i.é., respondia sequencialmente "cama" mesmo quando o exercício se tratava de outra palavra ou imagem no estímulo-modelo). O vídeo-reforço com a intenção de funcionar como punição positiva não 
alterava sua resposta. Sua estratégia dificilmente mudava, como se ela não tivesse aprendido nem mesmo a primeira relação reforçada. "D" repetia a primeira resposta (a única que obteve reforço positivo), sem tentar algo novo.

Vendo essas relações que "D" estava estabelecendo, planejou-se novas aulas baseadas nas atividades de ensino de palavras que a aluna já tinha feito. Nessas aulas, foram ensinadas todas as sílabas envolvidas nas atividades que ela faria a seguir. Depois, foi ensinado como essas sílabas formavam as palavras que se almejava que "D" aprendesse.

A escolha por essas novas aulas para "D" foi feita em cima de uma análise cuidadosa dos erros que ela vinha cometendo nas aulas iniciais do programa. A partir das Hipóteses de Escrita de "D", foi planejada a atividade silábica, aplicada e avaliada na atividade de teste pós-ensino para analisar o resultado sobre a silabação. O desempenho de " $D$ " nessa etapa foi muito bom e aumentou seu interesse nas atividades, contribuindo para motivá-la a permanecer no projeto.

O objetivo com as atividades de silabação foi de ajudá-la a identificar as partes das palavras e deixá-la mais segura para as atividades posteriores. Esse desempenho parece ter influenciado em atividades não diretamente relacionadas a elas (como de cores e números), e "D" ficou mais confiante para procurar estratégias alternativas para as respostas, deixando mais fácil para as monitoras estimulá-la a escolher uma opção de resposta na atividade. Depois da aplicação da aula de sílabas, seu rendimento em atividades reforçadas subiu de $50 \%$ para $90 \%$, ainda que nas atividades sem reforço o resultado tenha oscilado: ora atingiu também $90 \%$, ora mal alcançou $70 \%$. Por conta da efetividade na autoconfiança, continuou-se a planejar e aplicar "SIL" para todas as atividades de palavras do Mestre.

" $D$ " passou a identificar as palavras pelo som delas com maior eficiência. O tempo de resposta também diminuiu; entretanto, na hora de escrever sem modelo de referência, "D" quase sempre pulava consoantes, demonstrando sua habilidade com as vogais. Também não demonstrou ter produzido as relações de simetria e transitividade entre imagem e texto, nos exercícios de equivalência de cor.

Mais à frente, nas atividades de agrupamento, onde ela precisa ler cores, números e palavras juntas, ajudou-se "D" a criar alternativas para as consoantes, ensinando-a a agrupar sílabas para quando não soubesse por qual letra começar a leitura. Os resultados das últimas atividades foram excelentes; sua equivalência de agrupamento foi de $94 \%$ de acerto, o melhor índice entre as participantes.

A dificuldade de " $\mathrm{D}$ " talvez não aparecesse em sala de aula porque a aluna não 
requisitava tanto a mediação de sua professora. Nas atividades do Mestre ${ }^{\circledR}$, mesmo parecendo concentrada na atividade, ao ser indagada sobre como encontrar a resposta certa, percebeu-se que " $\mathrm{D}$ " não conseguia hipotetizar alternativas para resolver o problema e permanecia sem pedir ajuda e sem responder à questão. Quando a ajuda era-lhe ofertada, aceitava-a imediatamente com demonstração de alívio. Supõe-se que isso também ocorre em sala de aula, porém, como a topografia do comportamento de " $\mathrm{D}$ " pode ser facilmente confundida com concentração (em silêncio, em frente à atividade), a aluna pode não receber a oferta de ajuda, deixando suas dificuldades encobertas e explicando a demora da professora no seu encaminhamento ao projeto.

As atividades do Mestre ${ }^{\circledR}$ permitiram trazer à tona a clareza dos problemas de " $\mathrm{D}$ " e traçar alternativas para resolvê-los, algo difícil de ocorrer numa sala de aula com vários alunos e só uma educadora e uma auxiliar de ensino. O auxílio exclusivo a "D" em seu processo de ensino-aprendizagem lhe foi importante para a efetividade do trabalho conduzido, já que a aluna não apresentava o comportamento de procurar ajuda. Com o apoio exclusivo à "D", ao final do projeto, seu desempenho foi melhor que o de "A" e "B", superando expectativas.

"E" foi a última aluna a ser encaminhada, e isso se deu algumas aulas depois de "D". Ela já havia tido contato com o Mestre ${ }^{\circledR}$ durante uma pesquisa acadêmica acerca do programa, no mesmo ano em que entrou no projeto. Indicou-se a aluna para reforçar a alfabetização e por também apresentar atraso em relação aos colegas. Ela estava em aulas de reforço particulares e seu desempenho foi excelente, portanto, não percebemos a real eficiência do Mestre ${ }^{\circledR}$ no seu processo de ensino e aprendizagem. Ela apresentava excelentes resultados em quase todas as atividades - apenas uma esteve abaixo de $70 \%$ de acerto e sua grande maioria estava acima de $90 \%$. Sua motivação a continuar as atividades era estável até que o nível de dificuldade das aulas aumentou, com palavras novas e mais complexas. Percebeu-se que a aluna já havia passado por sensibilização em torno do erro: quando errava durante as atividades, apresentava efeitos fisiológicos como suor e tensão, ou na antecipação destes (respostas de tensão: respiração audível sem emitir voz alguma, posição rígida na cadeira sem apoiar as costas).

Durante a atividade de agrupamento, mais difícil que as aulas iniciais, sua frequência de tentativa caiu de modo a quase desistir por não saber se estava acertando ou errando (esta atividade não é programada para exibir vídeo-reforço). A incerteza proporcionava-lhe medo do erro. "E" havia estabelecido uma relação com as atividades do Mestre ${ }^{\circledR}$ por terem sido 
estabelecidas com múltiplos acertos sem grandes dificuldades, facilitadas possivelmente pelas aulas particulares, o que apenas a sensibilizou mais ao erro. Compreende-se que suas tentativas diminuíram em interesse, frequência e tempo de escolha quando não conseguia resolver a questão tão fácil e seguramente quanto todas as outras que já havia resolvido.

Nas atividades em que ela tinha certeza de qual opção era correta, "E" foi capaz de resolvê-las sem dificuldade, assim como a própria atividade 20, quando sua monitora indicou outras variáveis as quais deveria ficar atenta. Antes disso, a certeza sobre estar errando a paralisava, mesmo tendo capacidade para acertá-las. Talvez isso se deva às experiências anteriores, que contribuem para estigmatizar sua identidade em relação ao seu nível de capacidade.

Essa espécie de desamparo - não saber com clareza o que fazer, e seu autoconceito depender do resultado de sua escolha - havia sido superada por ela quando passou a ter aulas de reforço particulares, ministradas por um adulto próximo a ela. Ter um sistema de apoio à sua aprendizagem que a inteirava a deixou mais confiante, não apenas para realizar as atividades do Mestre ${ }^{\circledR}$, mas também para interagir sem impedir-se por medo.

Para "E”, o Mestre ${ }^{\circledR}$ não representou nenhum desafio, a não ser as atividades de agrupamento. Essas atividades a deixavam ansiosa quando não havia o reforço, necessitando do reforço das monitoras para continuar a atividade, e assim acertava consideravelmente. Portanto, para "E", o Mestre ${ }^{\circledR}$ não foi de grande eficiência como para as outras participantes.

Todas as participantes apresentaram desenvolvimento relacionado à destreza na manipulação do equipamento envolvido, facilitando o processo de inclusão digital. Essa destreza esteve em desenvolvimento ao longo do programa de forma pouco perceptível, em pequenos detalhes. Isso se manifestou de formas diversas, como por exemplo, movimentar o mouse em um espaço pequeno de mesa; ou manter o clique numa resposta e arrastar o cursor, fazendo com que a resposta seja anulada, e obter, assim, uma segunda chance para respondêla. Estas pequenas descobertas, ou problemas solucionados, permitem que as possibilidades de manipulação do equipamento cresçam, favorecendo a estimulação à curiosidade.

\section{CONSIDERAÇÕES FINAIS}

O objetivo de promover inclusão digital dos participantes do projeto foi estabelecido com vistas ao leque de possibilidades que as atividades do Mestre ${ }^{\circledR}$ proporcionariam. Isso não significa necessariamente que as crianças estão notoriamente a par do mundo digital, mas 
sim que o processo de desenvolvimento de habilidades requisitadas para interagir eficientemente neste mundo foi iniciado e, o mais importante, de maneira estimulante.

Sugerir ao repertório da professora novas ferramentas de ensino também era objetivo do projeto. Considera-se que esse objetivo foi parcialmente cumprido, pois a professora envolvida conheceu o software, procurando entender seu funcionamento e como ele poderia ser aproveitado na alfabetização. Todavia, nenhum dos profissionais da equipe (professora e estagiárias) teve disponibilidade para aprender a usar o Mestre ${ }^{\circledR}$ durante a aplicação do projeto, e o programa depende ainda de outros profissionais para ser aplicado.

Normalmente a alfabetização segue o método consoante+vogal, o que limita o vocabulário da criança a palavras e frases bem diferentes do que percebem no seu dia a dia. Essa maneira de organizar o ensino é feita com base no que os adultos que já sabem ler e escrever pensam sobre a alfabetização, sem considerar que as crianças não têm acesso ao "Mundo das Letras" só na escola. Elas recebem informação todo o tempo e as assimilam sem a organização que desejamos, acabando por não conseguir estabelecer uma comunicação clara em ambas as vias no processo de ensino e aprendizagem. "As crianças aprendem sobre letras, sons, palavras, produção/compreensão de textos, ao mesmo tempo, e em várias ordens, como também desenvolvem estratégias de monitoramento e de auto-correção" (Sulzby, 1992 apud Goulart, 2000, p. 159).

Uma das prioridades do projeto era respeitar e aproveitar cada hipótese de escrita das participantes. O Mestre ${ }^{\circledR}$ é uma excelente ferramenta para qualquer professor que queira ensinar seus alunos respeitando a singularidade de cada um em seu processo de aprender, reforçando a cada passo e permitindo que cada um tenha o seu tempo para processar a aprendizagem. Utilizando do software com um computador de configurações básicas, cada aluno poderá fazer a atividade em seu ritmo, e ao fim é possível diagnosticar, pelos erros cometidos, quais as dificuldades e quais as prováveis hipóteses da criança, para assim planejar um programa de ensino que efetue sua alfabetização.

Mesmo com todos os problemas que um software antigo tem - telas com cores fortes demais, desenhos ultrapassados, poucas opções, vídeos de reforços que se tornam enfadonhos no processo, estímulos modelos muito limitados — suas possibilidades são enormes. Qualquer conteúdo pode ser ensinado, e para qualquer público. É preciso destacar que há uma nova versão: Mestre LIBRAS ${ }^{\circledR}$ (Goyos; Elias; Ribeiro, 2005), que já corrige alguns problemas acima destacados, mas que deixa a desejar em facilidade e design.

Foi observado que parte das dificuldades encontradas no início do projeto pelas 
participantes advinham das diferentes letras usadas pelo programa: o software usava um "a" minúsculo em um formato desconhecido pela maioria das participantes, e a relação entre som e palavra não se estabelecia; imagens como "mago" e "foca" também eram desconhecidas para algumas participantes, demonstrando a importância da adequação das aulas para aqueles que vão fazê-las.

O trabalho também permitiu ensinar às monitoras muito no que tange à observação direta do comportamento, já que boa parte dos resultados deve-se a intervenções feitas durante a monitoria sobre o que era observado e discutido por ambas. Aprendeu-se a olhar para as participantes e entender o que os comportamentos apresentados indicavam sobre suas relações com o Mestre ${ }^{\circledR}$, com a alfabetização e outras relações escolares diversificadas em cada caso.

Recomenda-se que o projeto continue de forma planejada para que seus trabalhos se iniciem desde o início do ano letivo, assim alunos de outras séries poderão beneficiar-se dele, período no qual normalmente apresentam dificuldade em leitura. Também seria importante acompanhar as alunas que já participaram do programa para consolidar os resultados.

\section{REFERÊNCIAS}

CANABARRA, T. M. e outros. Análise Funcional de uma amostra de interações educativas ocorridas entre professora-alunos, em sala de aula, 2006. Disponível em: $<$ http://www.unimep.br/phpg/mostraacademica/anais/4mostra/pdfs/577.pdf > Acesso em: 30 Nov 2009.

GINDRI, G.; KESKE-SOARES, M.; MOTA, H. B. Memôria de trabalho, Consciência fonológica e hipótese de escrita. Pró-Fono Revista de Atualização Científica, Barueri (SP), v. 19, n. 3, p. 313-322, jul./set. 2007.

GOULART, C. M. A apropriação da linguagem escrita e o trabalho alfabetizador na escola. Cadernos de Pesquisa, n. 110, p. 157-175, jul. 2000.

GOYOS, C.; ALMEIDA, J. C. Mestre 1.0 [computer software]. São Carlos, SP. 1994.

KUBO, O. M. BOTOMÉ, S. P. Ensino-Aprendizagem: Uma Interação entre dois Processos Comportamentais. Interação, Curitiba, 5, p. 123-132, 2001. Disponível em: $<$ http://ojs.c3sl.ufpr.br/ojs2/index.php/psicologia/article/viewFile/3321/2665> Acesso em: 30 nov. 2009.

MEDEIROS, J. G. et al, A. C. S. A função da nomeação oral sobre comportamentos emergentes de leitura e escrita ensinados por computador. Estudos de Psicologia, n. 9, v. 2, p. 249-258, 2004. 
ROSSIT, R. A. S. Matemática para Deficientes Mentais: Contribuições do Paradigma de Equivalência de Estímulos para o Desenvolvimento e Avaliação de um Currículo. Tese de Doutorado. Programa de Pós-graduação em Educação Especial. Universidade Federal de São Carlos, 2003.

SIDMAN, Murray. A aprendizagem-sem-erros e sua importância para o ensino do deficiente mental. Psicologia: revista quadrimestral, Ano 11, n. 3, 1985.

SOUZA, B. P. Trabalhando com dificuldades na aquisição da língua escrita (137-163). In: Orientação à Queixa Escolar. São Paulo: Casa do Psicólogo, 2007. 